\title{
Tribological study of Al-6063-based metal matrix embedded with $\mathrm{SiC}-\mathrm{Al}_{2} \mathrm{O}_{3}-\mathrm{TiO}_{2}$ particles
}

\author{
Md. Bengir Ahmed Shuvho ${ }^{1,2}\left(\right.$ Dohammad Asaduzzaman Chowdhury ${ }^{2} \cdot$ Nayem Hossain $^{3} \cdot$ Biplov Kumar Roy $^{2}$. \\ Md. Arefin Kowser ${ }^{2} \cdot$ Azizul Islam²
}

Received: 7 September 2019 / Accepted: 17 January 2020 / Published online: 29 January 2020

(c) Springer Nature Switzerland AG 2020

\begin{abstract}
Aluminium-based metal matrix composites play a significant role in the field of aerospace, automobile, structural, and military applications due to their enhanced mechanical and tribological properties that contrasted to monolithic materials. Severe metal service conditions, such as cutting, grinding, and drilling and demand tribological and mechanical properties, must be improved. Metal matrix composites (MMCs) reinforced with filler particles are covenant materials for rectifying these issues. This study experimentally investigated the effect of normal load and sliding velocity on the friction and wear properties of Al-6063-based MMC embedded with filler particles. Experiments were conducted under normal loads of $5 \mathrm{~N}, 7.5 \mathrm{~N}$, and $10 \mathrm{~N}$ and velocities of $0.5 \mathrm{~m} / \mathrm{s}, 1 \mathrm{~m} / \mathrm{s}$, and $1.5 \mathrm{~m} / \mathrm{s}$. The experimental results revealed controlling friction and wear rate of aluminium-based MMC. The friction coefficient and wear resistance were improved by the aluminium-based MMC. The morphology of the metal matrix composites was analysed through scanning electron microscopy (SEM) and energy-dispersive X-ray (EDS). The applied load, sliding velocity, $\mathrm{SiC}, \mathrm{Al}_{2} \mathrm{O}_{3}$, and $\mathrm{TiO}_{2}$ significantly affect the friction coefficient and wear loss. Chemical properties were investigated through Fourier-transform infrared (FTIR) analysis, and the peak values were identified. The analysis can be used to predict the tribological properties of Al-6063 MMC in engineering applications.
\end{abstract}

Keywords Wear rate $\cdot$ Friction coefficient $\cdot$ Normal load $\cdot$ Sliding velocity $\cdot$ SEM $\cdot$ EDS $\cdot$ FTIR

\section{Introduction}

Particulate-reinforced metal matrix composite (PRMMC) is formed by the combination of metal and hard particles to achieve properties that are superior to those of its components. Among metallic matrices, the aluminium-based metal matrix remains the most observed material because it has suitable matrix-particle bonding, facile control of the matrix structure, simplicity, reasonable processing cost, and wide material selection. It has enchanting properties, such as high specific stiffness, low density, increased fatigue resistance, controlled coefficient of thermal expansion, and superior dimensional stability at elevated temperatures [1-15]. When density is low, PRMMC exhibits higher strength and stiffness and isotropic behaviour compared with unreinforced matrix materials [16]. However, tribological and mechanical characteristics of composites depend mostly on the matrix material's composition, size, and volume fraction at the reinforcing phase and the methods of fabrication. Several factors influence the distribution of filler particles in the matrix, such as rheological behaviour, uniform mixing of filler particles, and

$\triangle$ Md. Bengir Ahmed Shuvho, bengir.duet@gmail.com; Mohammad Asaduzzaman Chowdhury, asadzmn2014@yahoo.com; Nayem Hossain, shohelisme@gmail.com; Biplov Kumar Roy, biplov_007@yahoo.com; Md. Arefin Kowser, nadimduet@yahoo.com; Azizul Islam, aim1492@gmail.com | ${ }^{1}$ National Institute of Textile Engineering and Research (NITER), Savar, Dhaka 1350, Bangladesh.

${ }^{2}$ Department of Mechanical Engineering, Dhaka University of Engineering and Technology (DUET), Gazipur 1707, Bangladesh.

${ }^{3}$ Department of Mechanical Engineering, International University of Business Agriculture and Technology (IUBAT), Dhaka 1230, Bangladesh. 
congruence between the filler and matrix material with time and temperature. Electrical, mechanical, and chemical properties can be achieved by using different types of reinforcements, such as continuous, discontinuous, flake, and short fibres, with MMC.

The melt stir casting process is utilized to fabricate the aluminium-based metal matrix composites. Stir casting is one of the most established techniques for developing metal matrix composites. Stir casting is performed commercially due to its flexibility, simplicity, and applicability to large-quantity production. Moreover, stir casting allows conventional metal processing and thus minimizes the total product cost. The cost of preparing MMC using a casting method is about one-third to half that of other competitive methods, and for high-volume production, the cost is projected to decrease to one-tenth [12].

The stir casting method is used to obtain suitable dispersion. Solidification of the melt containing suspended silicon carbide ( $\mathrm{SiC}$ ) particles is accomplished under selected conditions to obtain the desired configuration. Kaleemulla et al. [16] investigated wear behaviour of Al-7075-based metal matrix composite reinforced with $\mathrm{SiC}$ particles. They investigated that wear behaviour is enhanced due to the presence of SiC.

Mital et al. [17] studied particulate-reinforced metal matrix composites using mechanics of materials approach, meaning the collection of physical principles, assumptions, approximations, mathematical models employed to relate the behaviour of metal matrix composites.

Srivatsan et al. [18] studied the discontinuous particlereinforced 6061 aluminium alloy cyclically deformed to failure at ambient temperature under stress amplitude in controlled conditions. The fundamental mechanisms leading to fracture behaviour included mutually interactive effects of the composite, microstructural, deformation characteristics and reinforced particles, nature of loading, and ductility. Srivatsan et al. [19] analysed the tensile properties and fracture characteristics of the aluminium alloy discontinuously reinforced with SiC. Tjong et al. [20] performed tensile creep tests at $573-673 \mathrm{~K}$ on pure aluminium, and aluminium-based composites reinforced with SiC particles with sizes of $3.5,10$, and $20 \mu \mathrm{m}$ were fabricated via powder metallurgy (PM) techniques.

Zhang et al. [21] studied aluminium-based metal matrix composite (MMC) reinforced with graphene and $\mathrm{Al}_{2} \mathrm{O}_{3}$ to improve the tribological properties of MMC. Since graphene is the self-lubricating material, graphene may be used as a reinforcing phase. $\mathrm{Al}_{2} \mathrm{O}_{3}$ and $\mathrm{TiO}_{2}$ as the reinforcing phase will enhance the strength of the MMC as compared to the base material [16].
It is identified from the literature that researches were conducted on tribological behaviour of metal matrix composites reinforced with particles. In this context, the research gaps imply that there is considerable scope for current researchers for investigation of the tribological behaviour of metal matrix composites (MMCs) with the combination of oxide or ceramics particles such as $\mathrm{SiC}$, $\mathrm{Al}_{2} \mathrm{O}_{3}$, and $\mathrm{TiO}_{2}$ as reinforcement. Thus, this study emphasizes on tribological behaviour of MMC. The main objective of this study is to develop MMC to improve the tribological characteristics of the composite.

In this research, the effects of the reinforced particle size of about 300 mesh (47 microns) and weight fractions of $2.5 \%, 5 \%, 7.5 \%$, and $10 \%$ on particle-reinforced composite materials were observed. Tribological properties, such as variation in sliding speed and normal load, were investigated to observe the friction coefficient and wear rate. The results contribute to the improvement of different mechanical processes such as the design and construction of the mechanical structure, automotive, aerospace, and machining processes such as cutting, drilling, turning, and grinding [22]. The acquired results also elucidate the relation between friction/wear and different deposition conditions of different materials under vibration at different normal loads and sliding velocities. This work explored the possibility of adding controlled normal load, sliding velocity, and the necessity of the effect of vibration on tribological behaviour to improve mechanical performance and quality.

\section{Materials and methods}

\subsection{Materials preparation}

Al 6063 alloy was used as a matrix material. The Al-6063 sample was collected from Altech Aluminium Industries Ltd., Bangladesh. The stir casting process was utilized for synthesizing the aluminium-based metal matrix composites (MMCs) since it is a simple and economical way of fabricating aluminium metal matrix composites. Al-6063 alloy was melted in a crucible by heating in a gas-fired furnace at $650^{\circ} \mathrm{C}$ for $4 \mathrm{~h}$. The reinforcement particulates ( $\mathrm{SiC}, \mathrm{TiO}_{2}$, and $\mathrm{Al}_{2} \mathrm{O}_{3}$ ) were preheated at $900{ }^{\circ} \mathrm{C}$ for $2 \mathrm{~h}$ to avoid the plunged gases from their surface and to avoid a high drop in temperature. The temperature of the furnace has been raised above the liquidus temperature of aluminium about $660^{\circ} \mathrm{C}$ to melt aluminium alloy completely and then cooled down just below the liquidus state to keep the slurry in the semisolid state. At every stage, automatic 
stirring was used at stirring speed of $400 \mathrm{rpm}$ for $8 \mathrm{~min}$. At this stage, preheated $\mathrm{SiC}, \mathrm{TiO}_{2}$, and $\mathrm{Al}_{2} \mathrm{O}_{3}$ particulates were introduced into the vortex of the molten alloy. In the final mixing process, the furnace temperature was controlled within $620 \pm 10{ }^{\circ} \mathrm{C}$ using a digital temperature controller. After the stirring process, the composite mixture was poured into the mould (dry sand mould) to get the desired shape.

\subsection{Experimental details}

A pin-on-disc tribometer was used in this experiment as shown in Fig. 1. The pin used was $\mathrm{SS} 304$, and aluminiumbased composites ( $\mathrm{Al} 6063-1 \%, \mathrm{TiO}_{2}-1 \%, \mathrm{Al}_{2} \mathrm{O}_{3}-2.5 \% \mathrm{SiC}$; Al $6063-1 \%, \mathrm{TiO}_{2}-1 \%, \mathrm{Al}_{2} \mathrm{O}_{3}-5 \% \mathrm{SiC} ; \mathrm{Al} 6063-1 \%, \mathrm{TiO}_{2}-1 \%$, $\mathrm{Al}_{2} \mathrm{O}_{3}-7.5 \% \mathrm{SiC}$; and $\mathrm{Al} 6063-1 \%, \mathrm{TiO}_{2}-1 \%, \mathrm{Al}_{2} \mathrm{O}_{3}-10 \% \mathrm{SiC}$ ) were utilized as disc materials. Each experiment was conducted for $30 \mathrm{~min}$. The rotational speed and applied loads were varied to observe the change in friction throughout the experiments. In addition, before and after each experiment, the weight of the specimen was measured using a digital weighing balance, and the difference between the measured values was the wear rate. A $17-\mathrm{mm}$ frictional distance from the centre of the tested disc was maintained throughout the experiments. The detailed experimental conditions are presented in Table 1. Table 2 represents the name of the samples with different compositions of the tested disc material. SEM studies were carried out using Phillips XL30 incorporated with the EDX analysis detector.

\section{Results and discussion}

\subsection{Influence of normal load and sliding velocity on friction coefficient}

Figure 2 shows a comparison of the variations in friction coefficients with normal loads. The friction coefficients of pure Al 6063 were higher than those of Al-based composite materials. Moreover, the friction coefficients decreased with the increasing percentage of filler particles $\left(\mathrm{SiC}-\mathrm{Al}_{2} \mathrm{O}_{3}-\mathrm{TiO}_{2}\right.$ ) that have been embedded in the matrix. The friction coefficients decreased to approximately $74 \%$, $68 \%$, and $71.6 \%$ in all combinations when the normal loads were $5,7.5$, and $10 \mathrm{~N}$, respectively. However, at reduced applied loads, the contact of the asperities was minimized and resulted in a ploughing action, which increased the friction coefficient [23]. A previous study has shown that as the normal load increases, an oxide layer may form on the surface due to increased surface temperature, and this layer provides a self-lubricating action and reduces friction [24].

The friction coefficient of Al 6063 (Al $6063-\mathrm{SiC}-\mathrm{Al}_{2} \mathrm{O}_{3}-\mathrm{TiO}_{2}$ ) decreased to $73.6 \%, 58.5 \%$, and $63.1 \%$ when the sliding velocity was $0.5,1$, and $1.5 \mathrm{~m} / \mathrm{s}$ from the base alloy to the composite material, respectively, with an operating normal load of $5 \mathrm{~N}$. From Fig. 2, it can be examined that with the increasing normal load, friction coefficient is increased. However, the friction coefficient is

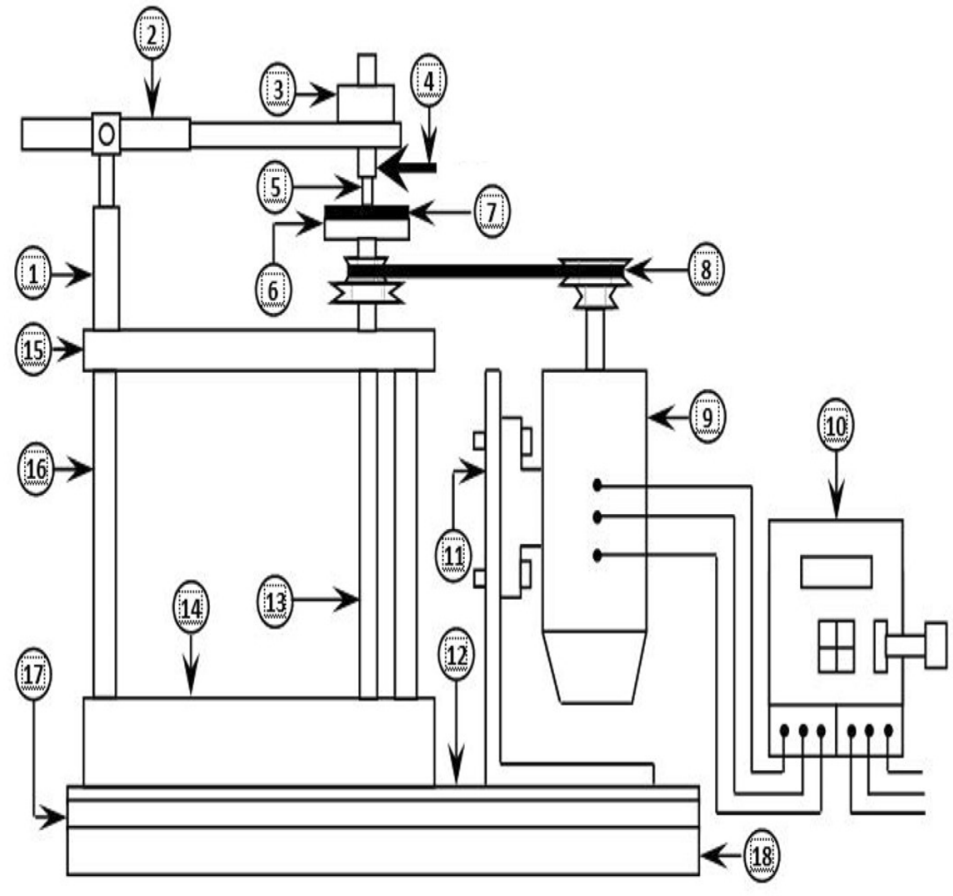

1. Load arm holder

2. Load arm

3. Normal load (dead weight)

4. Spring balance

5. Pin sample

6. Rotating table

7. Test disc

8. Belt and pulley

9. Motor

10. Speed control unit

11. Vertical motor base

12. $3 \mathrm{~mm}$ Rubber pad

13. Main shaft

14. Stainless steel base

15. Stainless steel plate

16. Vertical square bar

17. Mild steel main base plate

18. Rubber block

Fig. 1 Schematic view of the experimental setup 
Table 1 Experimental ranges and operating conditions of the parameters

\begin{tabular}{lll}
\hline SI. no. & Parameters & Operating conditions \\
\hline 1 & Normal load & $5,7.5$, and $10 \mathrm{~N}$ \\
2 & Sliding velocity & $0.5,1$, and $1.5 \mathrm{~m} / \mathrm{s}$ \\
3 & Relative humidity & $40( \pm 5) \%$ \\
4 & Duration of rubbing & $30 \mathrm{~min}$ \\
5 & Surface condition & Dry \\
6 & Disc material & $\mathrm{Al}(6063)$ \\
& & $\mathrm{Al}(6063)-2.5 \% \mathrm{SiC}-1 \mathrm{HAl}_{2} \mathrm{O}_{3}-1 \% \mathrm{TiO}_{2}$ \\
& & $\mathrm{Al}(6063)-5 \% \mathrm{SiC}-1 \% \mathrm{Al}_{2} \mathrm{O}_{3}-1 \mathrm{TiO}_{2}$ \\
& & $\mathrm{Al}(6063)-7.5 \% \mathrm{SiC}-1 \mathrm{Al}_{2} \mathrm{O}_{3}-1 \% \mathrm{TiO}_{2}$ \\
7 & $\mathrm{Al}(6063)-10 \% \mathrm{SiC}-1 \% \mathrm{Al}_{2} \mathrm{O}_{3}-1 \% \mathrm{TiO}_{2}$ \\
8 & Disc surface condition & $\mathrm{Turned}$ and ground \\
9 & Roughness & $0.80-0.90 \mu \mathrm{m}$ \\
10 & Pin material & $\mathrm{SS} \mathrm{304}$ \\
\hline
\end{tabular}

decreased with the increasing $\mathrm{SiC}$ particles and minimum at sample $\mathrm{S} 5$ [Al (6063)-10\% $\left.\mathrm{SiC}-1 \% \mathrm{Al}_{2} \mathrm{O}_{3}-1 \% \mathrm{TiO}_{2}\right]$.

The decrease in friction coefficient with the increase in sliding velocity was probably due to the change in the shear rate, which influenced the mechanical properties of the mating materials, as shown in Fig. 3a. The strength of these materials is high at higher shear strain rates $[14,15]$, resulting in a small actual area of contact and a low coefficient of friction in dry contact conditions. These results are in good agreement with the findings of Chowdhury et al. [25].

Figure $3 \mathrm{~b}$ shows the variation in friction coefficient with sliding velocity for different types of pin-disc combinations. The friction coefficient of Al 6063 (Al $6063-\mathrm{SiC}-\mathrm{Al}_{2} \mathrm{O}_{3}-\mathrm{TiO}_{2}$ ) varied by $68.3 \%, 81.3 \%$, and $75.4 \%$ when the sliding velocity was $0.5,1$, and $1.5 \mathrm{~m} / \mathrm{s}$, respectively, from the base alloy to the composite material at $7.5 \mathrm{~N}$ normal load.

Figure $3 \mathrm{C}$ indicates that the friction coefficient of $\mathrm{Al}$ $6063\left(\mathrm{Al} 6063-\mathrm{SiC}-\mathrm{Al}_{2} \mathrm{O}_{3}-\mathrm{TiO}_{2}\right.$ ) varied by $71.6 \%, 83.3 \%$, and $88.4 \%$ when the sliding velocity was $0.5,1$, and $1.5 \mathrm{~m} / \mathrm{s}$, respectively, from the base alloy to the composite material at $10 \mathrm{~N}$ operating normal load. However, the reduction in the friction coefficient of composites with increasing particles $\left(\mathrm{SiC}-\mathrm{Al}_{2} \mathrm{O}_{3}-\mathrm{TiO}_{2}\right)$ improved the antifrictional behaviour of the stir cast composites due to the lubricating effect of the particles $\left(\mathrm{SiC}-\mathrm{Al}_{2} \mathrm{O}_{3}-\mathrm{TiO}_{2}\right)$. Previous researchers have suggested that the presence of an oxide layer between mating surfaces reduces sliding friction $[25,26]$. It is observed that with the increasing sliding velocity, the friction coefficient is minimum at the highest percentage of SiC particles for S5 [AI (6063)-10\% SiC-1\% $\mathrm{Al}_{2} \mathrm{O}_{3}-1 \% \mathrm{TiO}_{2}$ ].

\subsection{Influence of sliding velocity and normal load on wear rate}

Figure $4 a$, b shows that the wear rate increased with increasing the applied load for all pin and disc combinations. However, it may be disclosed, at higher loads, and the oxides films slightly were removed, resulting in higher wear loss. When the load on the pin increased, the area of contact increased in relation to the nominal contact area, and this increased the frictional force between two contact sliding surfaces. The increased frictional force and actual contact surface area caused severe wear. Therefore, the frictional thrust and shear force increased with the

Table 2 Sample name of tested disc materials

\begin{tabular}{ll}
\hline Sample name & Testing material (disc materials) compositions \\
\hline S1 & $\mathrm{Al}(6063)$ \\
S2 & $\mathrm{Al}(6063)-1 \% \mathrm{Al}_{2} \mathrm{O}_{3}-1 \% \mathrm{TiO}_{2}-2.5 \% \mathrm{SiC}$ \\
S3 & $\mathrm{Al}(6063)-1 \% \mathrm{Al}_{2} \mathrm{O}_{3}-1 \% \mathrm{TiO}_{2}-5 \% \mathrm{SiC}$ \\
S4 & $\mathrm{Al}(6063)-1 \% \mathrm{Al}_{2} \mathrm{O}_{3}-1 \% \mathrm{TiO}_{2}-7.5 \% \mathrm{SiC}$ \\
S5 & $\mathrm{Al}(6063)-1 \% \mathrm{Al}_{2} \mathrm{O}_{3}-1 \% \mathrm{TiO}_{2}-10 \% \mathrm{SiC}$ \\
\hline
\end{tabular}



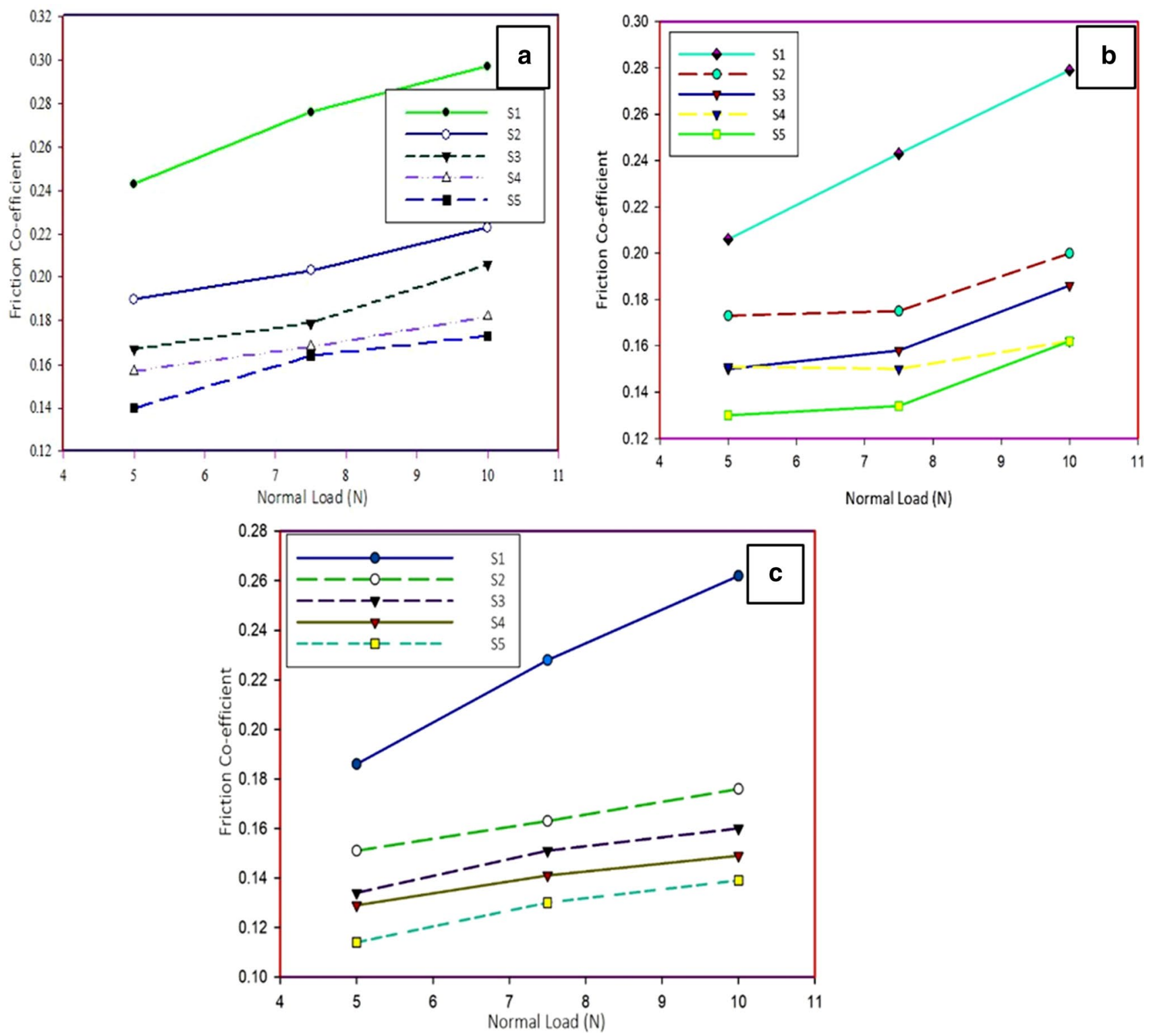

Fig. 2 Variation in friction coefficient with the variation in normal loads at a sliding velocity: $0.5 \mathrm{~m} / \mathrm{s}, \mathbf{b}$ sliding velocity: $1 \mathrm{~m} / \mathrm{s}$, c sliding velocity: $1.5 \mathrm{~m} / \mathrm{s}$; relative humidity: 40 ( $\pm 5 \%)$

increase in applied load and thus accelerated the wear rate. This is due to the clustering of reinforcing particles $\mathrm{SiC}, \mathrm{Al}_{2} \mathrm{O}_{3}$, and $\mathrm{TiO}_{2}$. The influence of sliding velocity on the friction coefficient was found to be inverse. At low speed, friction coefficient is high. As the speed increased, the rate of friction coefficient is decreased. Similar trends have been observed for aluminium [27]. These figures also show that the highest values of wear rate of Al 6063 disc were observed at identical conditions. The lowest values of wear rate ( $\mathrm{Al} 6063-10 \% \mathrm{SiC}-1 \% \mathrm{Al}_{2} \mathrm{O}_{3}-1 \% \mathrm{TiO}_{2}$ ) were also observed, and the results indicated that the wear rates of the Al 6063 disc were higher than those of the composite in all conditions.

Figure $4 c$ shows almost the same trend as that in Fig. 4a, b. However, initially, the sliding velocity increased with increasing wear rate compared with the last two 

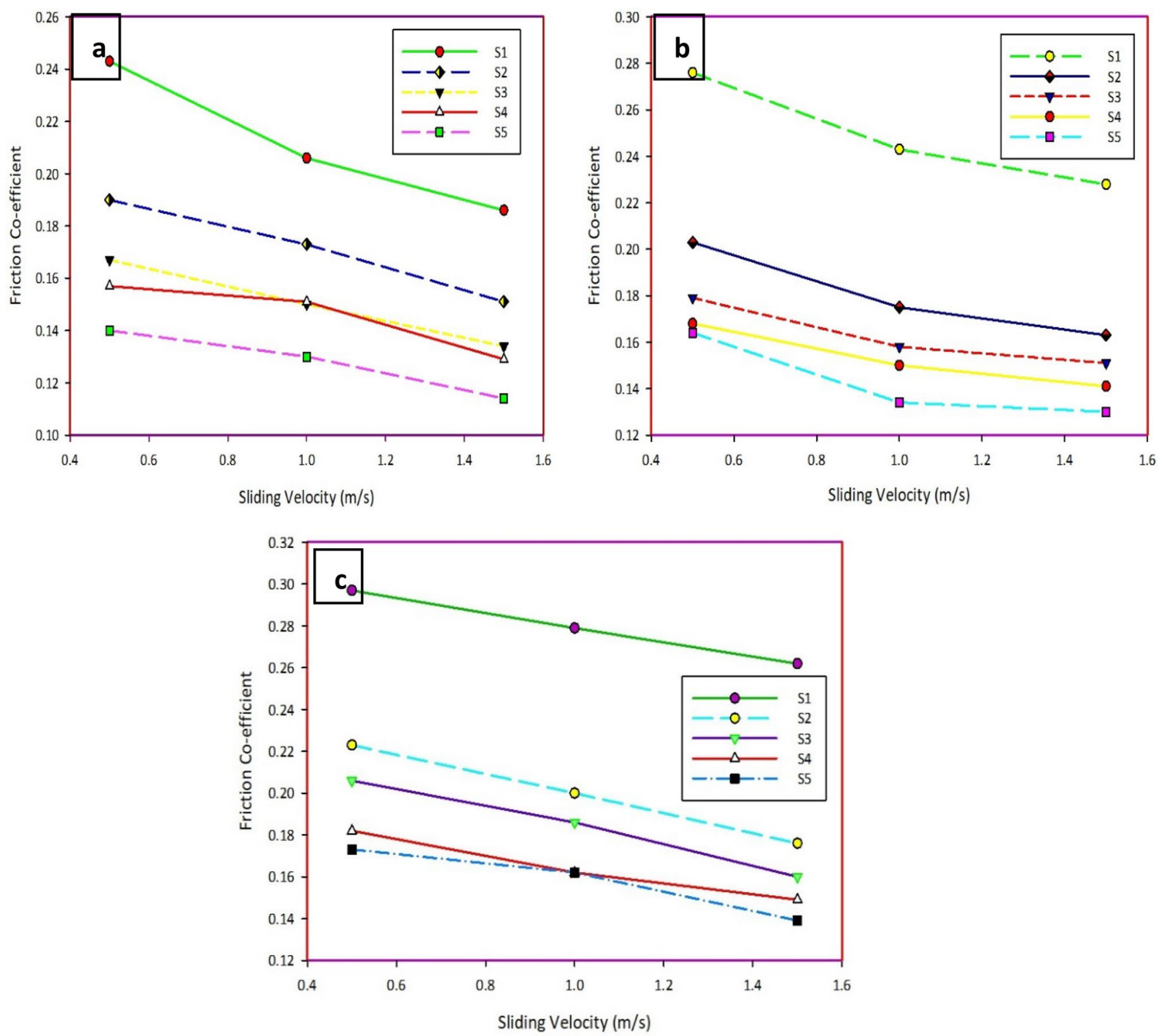

Fig. 3 Variation in friction coefficient with the variation in sliding velocities and pin-disc combinations at $\mathbf{a}$ normal loads: $5 \mathrm{~N}$, $\mathbf{b}$ normal loads: $7.5 \mathrm{~N}, \mathrm{c}$ normal loads: $10 \mathrm{~N}$; relative humidity: $40( \pm 5) \%$

conditions. The improvement in the wear resistance of the $\mathrm{Al} 6063\left(\mathrm{SiC}-\mathrm{Al}_{2} \mathrm{O}_{3}-\mathrm{TiO}_{2}\right)$-reinforced composites can be described by the following factors:

- The improvement of the hardness of fabricated composites was caused by the incorporation of hard (SiC$\mathrm{Al}_{2} \mathrm{O}_{3}-\mathrm{TiO}_{2}$ ) particles reinforced in the soft matrix alloy. The increase in hardness resulted in the development of the wear resistance of materials. The increasing hardness of the MMCs reduced the wear intensity. Experimental results from previous researches reveal that the incorporation of hard particles significantly improves the wear resistance of aluminium $[28,29]$.

- The interfacial bond between the particle $\left(\mathrm{SiC}-\mathrm{Al}_{2} \mathrm{O}_{3}-\right.$ $\mathrm{TiO}_{2}$ ) and matrix reinforcement played an apt role in the wear process. 

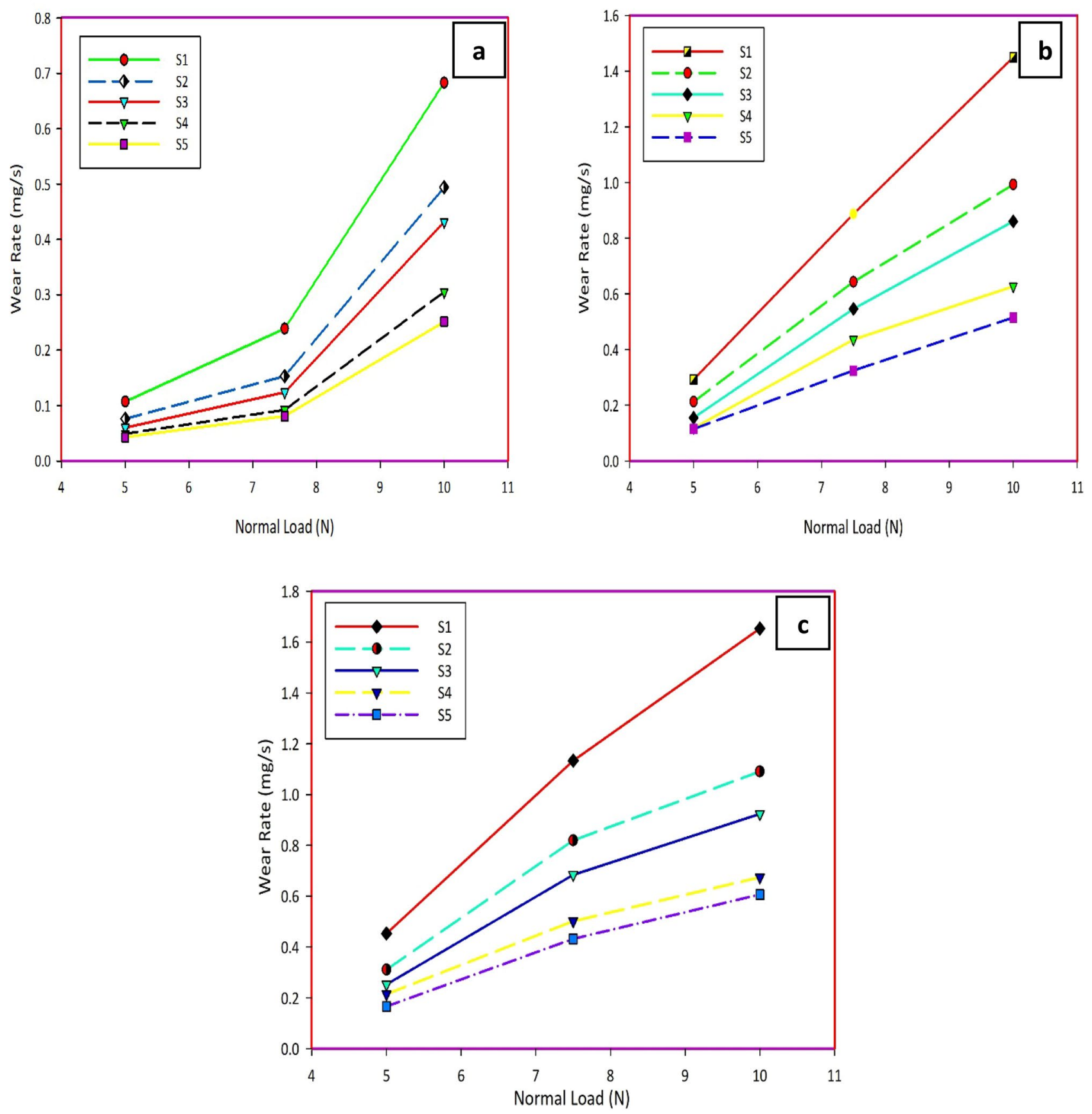

Fig. 4 Variation in wear rate with the variation in normal loads at different pin-disc combinations at a sliding velocity: $0.5 \mathrm{~m} / \mathrm{s}$, $\mathbf{b}$ sliding velocity: $1 \mathrm{~m} / \mathrm{s}$, c sliding velocity: $1.5 \mathrm{~m} / \mathrm{s}$; relative humidity: $40( \pm 5) \%$

Figure 5 a shows that the wear rate varied from 0.107 to $0.453 \mathrm{mg} / \mathrm{s}$ of base alloy Al 6063, and the consecutive decrease in wear rate was due to the particle composites $\left(\mathrm{SiC}-\mathrm{Al}_{2} \mathrm{O}_{3}-\mathrm{TiO}_{2}\right)$. The minimum wear rate from 0.043 to $0.166 \mathrm{mg} / \mathrm{s}$ was obtained for the maximum percentage of composite particles. A similar trend can also be observed in Fig. 5b, c for 7.5 and $10 \mathrm{~N}$ normal loads, respectively. When the hard particle $\left(\mathrm{SiC}-\mathrm{Al}_{2} \mathrm{O}_{3}-\mathrm{TiO}_{2}\right)$ increased, the wear rate increased significantly. Figure 6 shows the average values of the friction coefficient and wear rate with standard deviation error bars. 

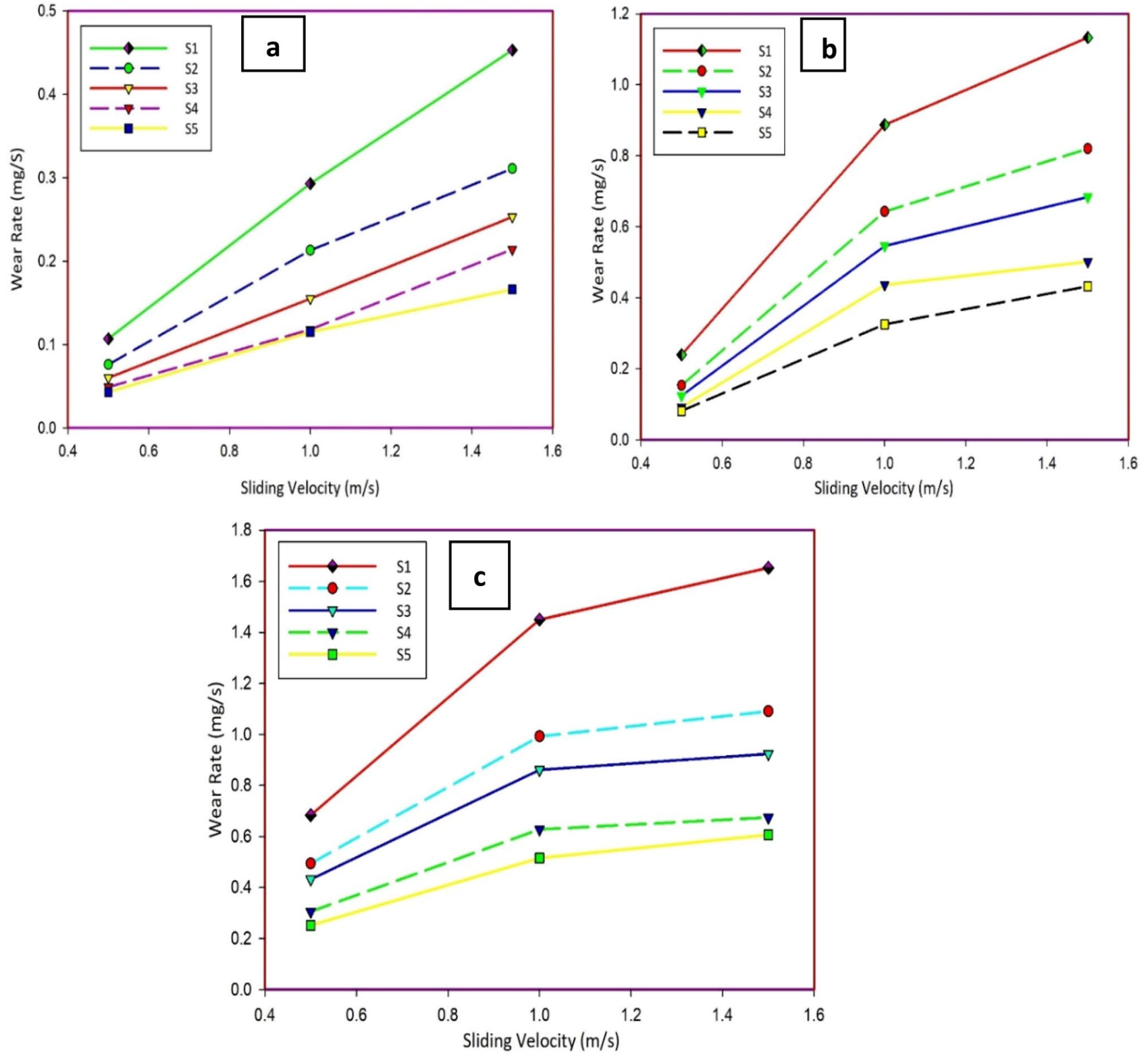

Fig. 5 Variation in wear rate with the variation in sliding velocity at different pin-disc combinations at a normal loads: $5 \mathrm{~N}, \mathbf{b}$ normal loads: $7.5 \mathrm{~N}, \mathrm{c}$ normal loads: $10 \mathrm{~N}$; relative humidity: $40( \pm 5) \%$

\subsection{Microstructure analysis}

The morphology of the rubbing and fracture surfaces is characterized by SEM analysis. The morphologies of the observed rubbing and fracture surfaces are in the microrange $(100 \mu \mathrm{m})$. Figure $7 \mathrm{a}-\mathrm{f}$ reveals that rubbing and fracture morphology are sharply affected by the microstructure. The SEM images (Fig. 7a-c) show wear debris, wear track, and accumulated roughing surfaces due to rubbing. The SEM images (Fig. 7d-f) show fracture, void, and microcrack surfaces. Due to microcrack and void, there is poor interfacial strength between 

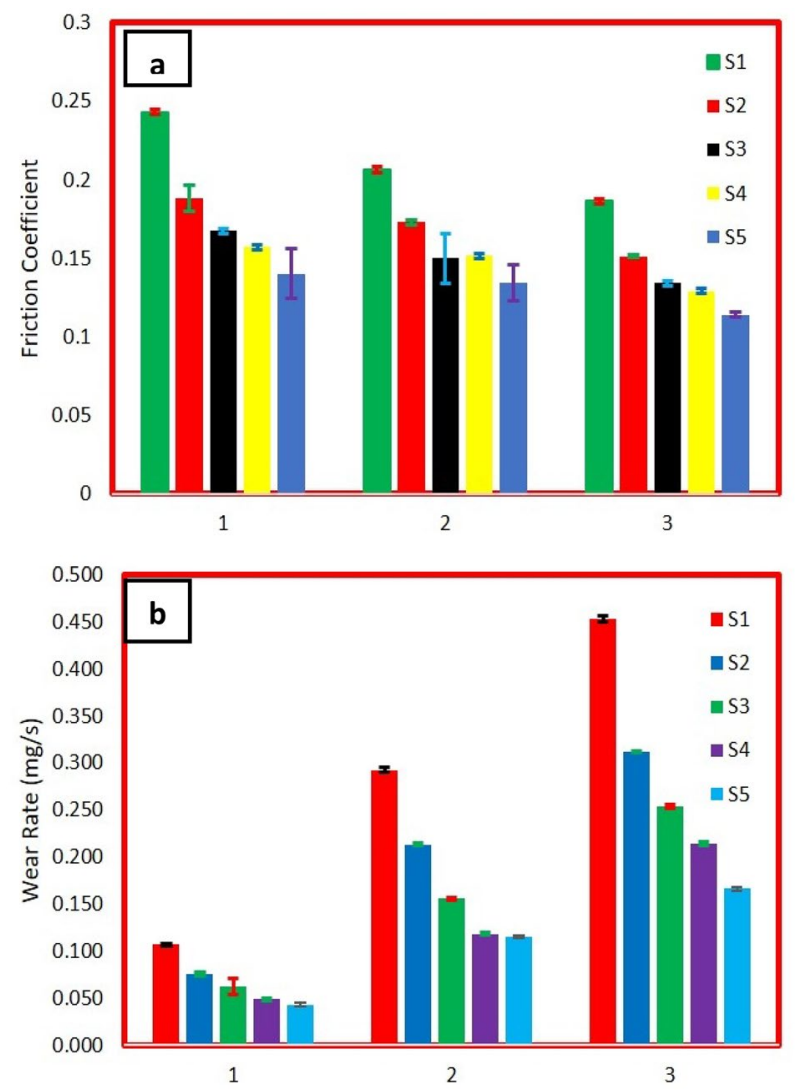

Fig. 6 Mean results with error bar standard deviation a friction coefficient, $\mathbf{b}$ wear rate

particles and matrix of the MMC. Also' this occurred due to wear rate and friction coefficient experimental analysis. Large-sized abrasive wear has been created due to the ploughing effect.

Figure 8 presents SEM and EDX micrographs of Al-84.31\%, C-13.86\%, O-1.57\%, and Si-.26\% composites. The maximum percentage of the composites contained aluminium. EDX spectra from several spot labels are also shown in Fig. 8. The microstructure shows the existence of other elements, such as $\mathrm{C}, \mathrm{O}, \mathrm{Si}$, and $\mathrm{Ti}$, which can be detected by Al peaks in the EDX spectra. In spot 0.16 , a strong peak of aluminium can be observed in the MMC. The formation of interfacial layers of $\mathrm{SiC}, \mathrm{Al}_{2} \mathrm{O}_{3}$, and $\mathrm{TiO}_{2}$ particles was confirmed by the exploration of the EDX result. Figure 9 shows almost homogeneous particle size distribution where the mean diameter of particles is found as $0.18 \mu \mathrm{m}$.

\subsection{FTIR analysis}

For identifying different chemical functional groups present in a sample [30], Fourier-transform infrared spectroscopy (FTIR) is a standard method as a nondestructive testing tool. The infrared absorption (FTIR) is shown in Fig. 10. Various major chemical functional groups such as $\mathrm{C}-\mathrm{H}$ stretching at $3200 \mathrm{~cm}^{-1}, \mathrm{C}=\mathrm{C}$ bend at $1650 \mathrm{~cm}^{-1}, \mathrm{~N}-\mathrm{H}$ bend at $1400 \mathrm{~cm}^{-1}$, and aromatic $\mathrm{sp}^{2}$ $\mathrm{C}-\mathrm{H}$ stretch at $1050 \mathrm{~cm}^{-1}$ were identified.

The results are mentioned above, and the higher the percentage of $\mathrm{SiC}$, the lower the friction coefficient and wear rate are observed at different operating conditions. Whenever the normal load is increased, friction and wear rates are increased, which explains the uniform distribution of reinforced particles as reported by the researchers [31, 32]. In case of non-productive frictional applications such as gears, cam, and bearing seals [33], the percentage of $\mathrm{SiC}$ can be increased with a lower level of the normal load. In productive frictions such as machining, polishing, and shaving, the vice versa is true [33]. Friction and wear rates are affected differently with the variation in other operating factors such as sliding velocity. From the SEM image, it is noticed that wear debris and ploughing effects are increased with the increase in sliding velocity. Similar trends are also observed by Ramesh et al. [31]. 

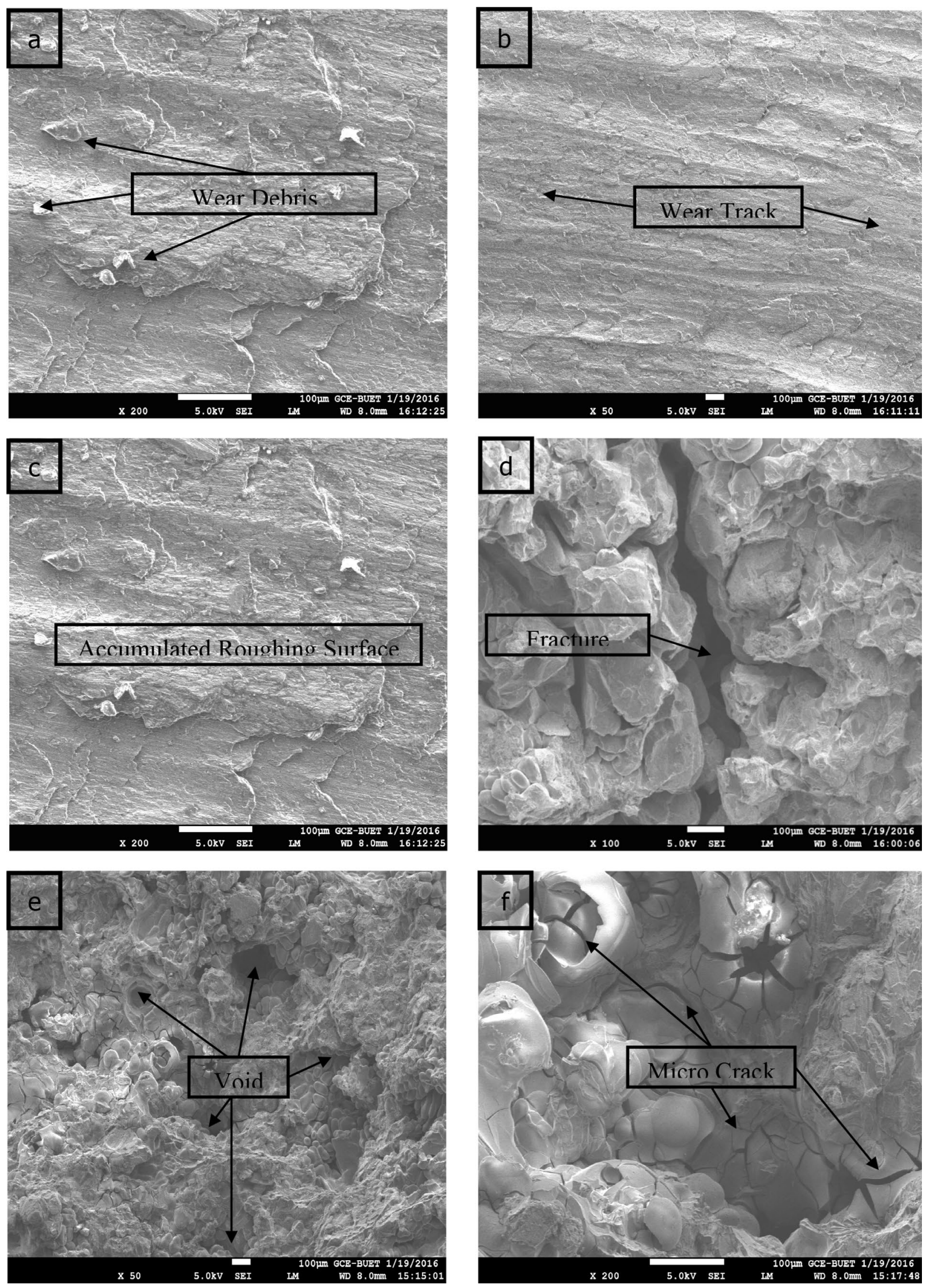

Fig. 7 SEM micrographs of the worn surfaces a wear debris, $\mathbf{b}$ wear track, and $\mathbf{c}$ accumulated roughing surface after rubbing and $\mathbf{d}$ fracture, e void, and $\mathbf{f}$ microcrack

SN Applied Sciences 
Fig. 8 EDX elemental results and backscattered of the microwave-sintered sample
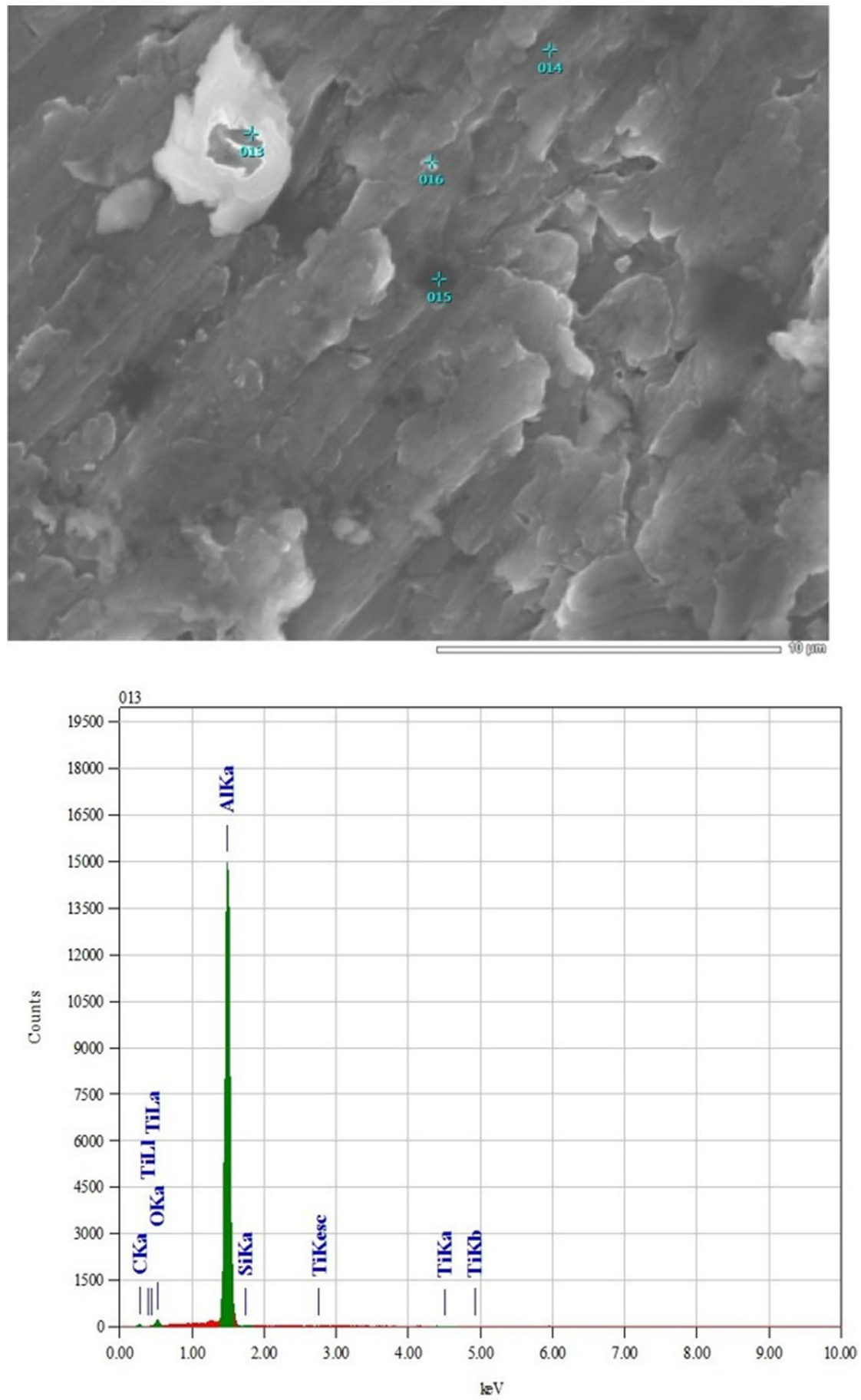

$\begin{array}{llllll}\text { Element } & (\mathrm{keV}) & \text { Mass\% } & \text { Sigma } & \text { Atom\% } & \text { Con } \\ \text { C K } & 0.277 & 13.86 & 0.35 & 26.31 & \\ \text { O K } & 0.525 & 1.57 & 0.04 & 2.24 & \\ \text { Al K } & 1.486 & 84.31 & 0.31 & 71.24 & \\ \text { Si K } & 1.739 & 0.26 & 0.04 & 0.21 & \\ \text { Ti K } & & & & & \\ \text { Total } & & 100.00 & & 100.00 & \end{array}$




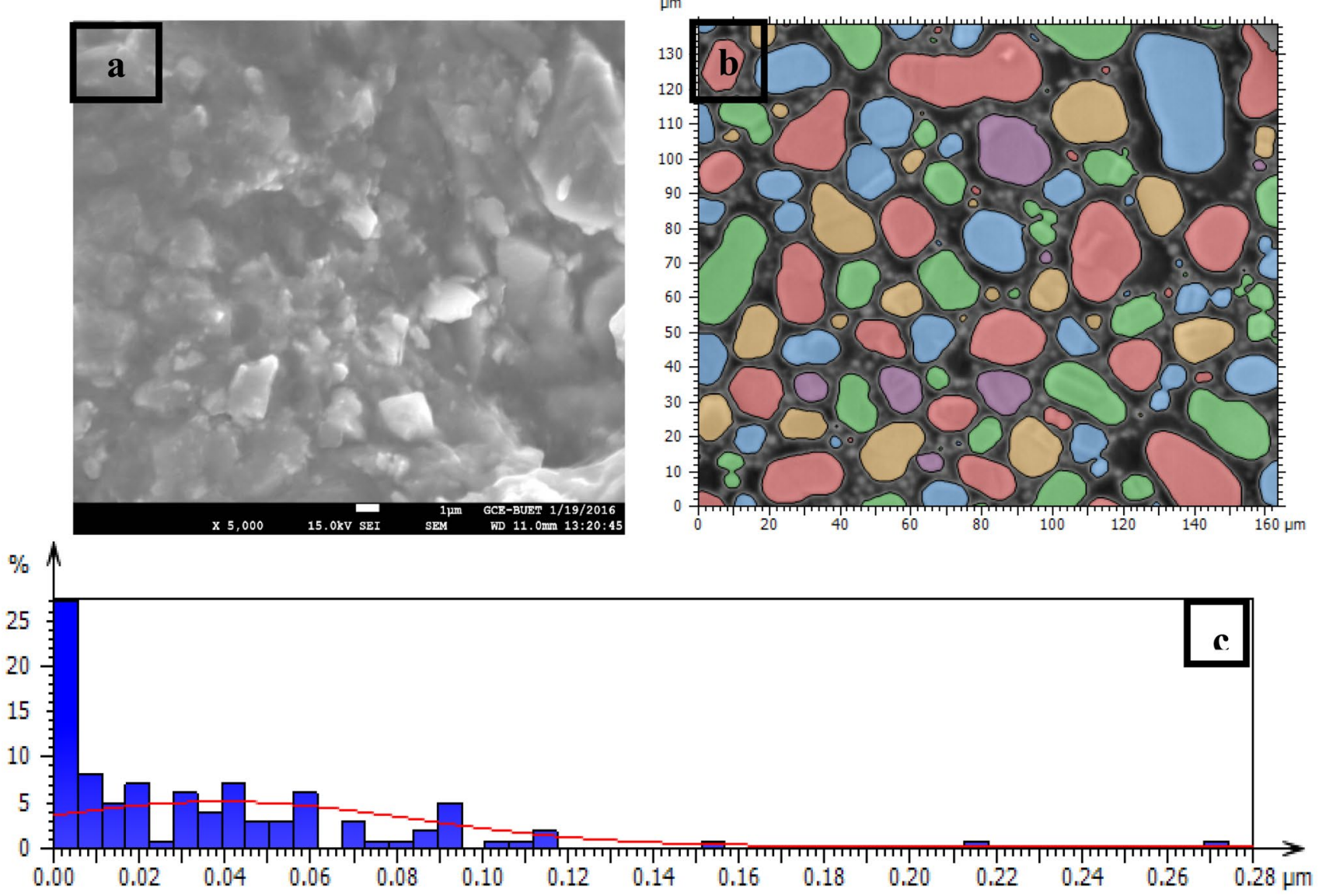

Fig. 9 a SEM image, b particle size distribution, and c corresponding histogram

Fig. 10 FTIR spectrum of Al-6063-based metal matrix composite

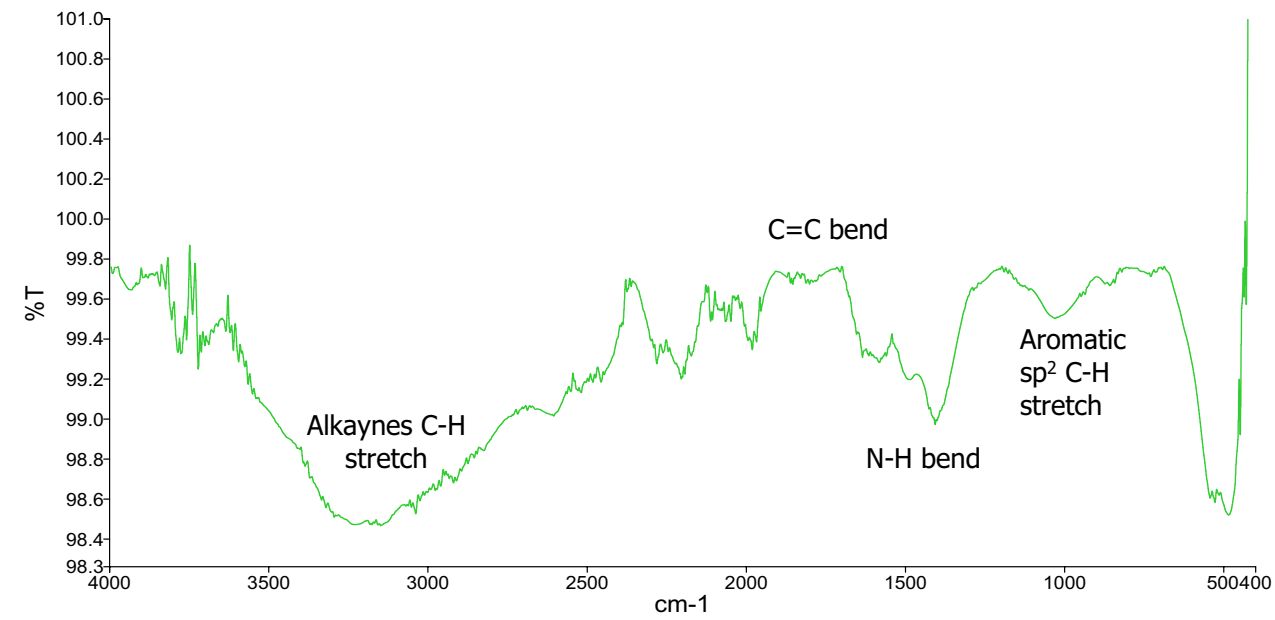

\section{Conclusion}

This study aims to reduce the friction and wear rate of aluminium-based metal matrix composite by varying $\mathrm{SiC}$ at different percentages. The effects of reinforced particles ( $\mathrm{SiC}, \mathrm{Al}_{2} \mathrm{O}_{3}, \mathrm{TiO}_{2}$ ), sliding velocity, normal load on wear rate and friction coefficient were studied. Whenever the percentage of SiC filler particles increases, friction coefficient and wear rate decrease gradually at a certain rate within the range of different operating 
conditions. These trends of results are observed due to the reduction in surface roughness, an increase in hardness at the top surface, and density. Moreover, the influence of an oxide layer $\left(\mathrm{Al}_{2} \mathrm{O}_{3}, \mathrm{TiO}_{2}\right)$ at the friction contact interface was responsible for the reduction of frictional force as well as to reduce the wear rate. Micrographs, FTIR, and EDX analysis were conducted and produced consistent results regarding the improved tribological properties. Morphological study reveals wear track, microcrack, void, and stack surface. The interfacial bond between the matrix and particle $\left(\mathrm{SiC}-\mathrm{Al}_{2} \mathrm{O}_{3}-\mathrm{TiO}_{2}\right)$ reinforcement played a significant role in the wear process. $\mathrm{SiC}, \mathrm{Al}_{2} \mathrm{O}_{3}$, and $\mathrm{TiO}_{2}$ particles within $\mathrm{Al}-6063$ matrix alloy were confirmed by the exploration of the EDS elemental mapping. The peak values were identified using FTIR analysis. The results disclose that the proper control of process parameters such as normal load and sliding velocity can result in the improvement of tribological properties. The reinforcement of $\mathrm{SiC}, \mathrm{Al}_{2} \mathrm{O}_{3}$, and $\mathrm{TiO}_{2}$ in aluminium matrix alloy significantly enhanced the tribological properties as the loads and sliding speeds increase and give the best results of wear rate and friction coefficient. From the above discussion and analysis, we conclude that Al-6063-based metal matrix composites reinforced with $\mathrm{SiC}, \mathrm{Al}_{2} \mathrm{O}_{3}$, and $\mathrm{TiO}_{2}$ should be preferred for low-speed applications. The similar results were observed in the literature [34].

\section{Compliance with ethical standards}

Conflict of interest The authors declare that they have no conflict of interest.

\section{References}

1. Kainer U (2006) Metal matrix composites: custom-made materials for automotive and aerospace engineering. Wiley, Hoboken

2. Suresh S, Mortensen A, Needleman A (1993) Fundamentals of metal matrix composites. Butterworth-Heinemann, London

3. Chawla N, Shen Y (2011) Mechanical behavior of particle reinforced metal matrix composite. Adv Eng Mater 3(6):357-370

4. Qian LH, Wang ZG, Toda H, Kobayashi T (2003) Effect of reinforcement volume fraction on the thermo-mechanical fatigue behavior of $\mathrm{SiC}_{\mathrm{W}} / 6061 \mathrm{Al}$ composites. Mater Sci Eng A 357(1-2):240-247

5. Thakur SK, Dhindaw BK (2001) The influence of interfacial characteristics between $\mathrm{SiC}_{\mathrm{p}}$ and $\mathrm{Mg} / \mathrm{Al}$ metal matrix on wear, coefficient of friction and micro hardness. Wear 247:191-201

6. Divecha AP, Fishman SG, Karmarkar SD (1981) Silicon carbide reinforced aluminum - a formable composite. J Met 33(9):12-17

7. Ray N, Kerketta DK (201) Some studies on aluminium matrix in situ composites produced by stir casting method. M.E. Thesis. NIT, Rourkela
8. Venkatesh R, Rao VS (2018) Thermal, corrosion and wear analysis of copper based metal matrix composites reinforced with alumina and graphite. Def Technol 14(4):346-355

9. Sankaranarayanan S, Karthigeyan R, Ranganath G (2012) Mechanical properties and microstructure studies of aluminium (7075) alloy matrix composite reinforced with short basalt fibre. Eur J Sci Res 68(4):606-615

10. Pujari S, Srikiran S (2019) Experimental investigations on wear properties of Palm kernel reinforced composites for brake pad applications. Def Technol 15(3):295-299

11. Swamy ARK, Ramesha A, Kumar GBV, Prakash JN (2011) Effect of particulate reinforcements on the mechanical properties of Al6061-WC and Al6061-Gr MMCs. J Miner Mater Charact Eng 10(12):1141-1152

12. Prasad BK (2007) Investigation into sliding wear performance of zinc-based alloy reinforced with $\mathrm{SiC}$ particles in dry and lubricated conditions. Wear 262:262-273

13. Lim T-C (2019) Metamaterials with Poisson's ratio sign toggling by means of microstructural duality. SN Appl Sci 1(2):176

14. Sajjadi SA et al (2011) Microstructure and mechanical properties of $\mathrm{Al}-\mathrm{Al}_{2} \mathrm{O}_{3}$ micro and nano composites fabricated by stir casting. Mater Sci Eng A 528:8765-8771

15. Ahmad SNAS, Hashim J, Ghazali MI (2007) Effect of porosity on tensile properties of cast particle reinforced MMC. J Compos Mater 41(5):575-589

16. Kaleemulla M, Doddamani S (2019) Material characterization of $\mathrm{SiC}$ and $\mathrm{Al}_{2} \mathrm{O}_{3}$-reinforced hybrid aluminum metal matrix composites on wear behavior. Adv Compos Lett 28:0963693519856356

17. Mital SK, Murthy PLN, Goldberg RK (1997) Micromechanics for particulate-reinforced composites. Mech Compos Mater Struct Int J 4(3):251-266

18. Srivatsan TS, Al-Hajri M, Petraroli M, Hotton B, Lam PC (2002) Influence of silicon carbide particulate reinforcement on quasi static and cyclic fatigue fracture behavior of 6061 aluminium alloy composites. Mater Sci Eng A 325:202-214

19. Srivatsan TS, Al-Hajri M, Petraroli M (2003) The tensile response and fracture behaviour of 2009 aluminium alloy metal matrix composite. Mater Sci Eng A 346(1):91-100

20. Tjong SC, Ma ZY (1999) High-temperature creep behaviour of powder-metallurgy aluminium composites reinforced with $\mathrm{SiC}$ particles of various sizes. Compos Sci Technol 59:1117-1125

21. Zhang $\mathrm{Y}, \mathrm{Li} X$ (2017) Bioinspired, graphene $/ \mathrm{Al}_{2} \mathrm{O}_{3}$ doubly reinforced aluminum composites with high strength and toughness. Nano Lett 17(11):6907-6915

22. Levashov E, Kurbatkina V, Alexandr Z (2010) Improved mechanical and tribological properties of metal-matrix composites dispersion-strengthened by nanoparticles. Materials 3(1):97-109

23. Hong SY, Ding Y, Jeong J (2002) Experimental evaluation of friction coefficient and liquid nitrogen lubrication effect in cryogenic machining. Mach Sci Technol 6(2):235-250

24. Bhushan B (1999) Principle and applications of tribology. Wiley, New York

25. Chowdhury MA, Helali MM (2008) The effect of amplitude of vibration on the coefficient of friction. Tribol Int 41(4):307-314

26. Maleque MA, Karim MR (2008) Tribological behavior of dual and triple particle size $\mathrm{SiC}$ reinforced Al-MMCs: a comparative study. Ind Lubr Tribol 60(4):189-194. https://doi.org/10.1108/00368 790810881533

27. Poorraeisi M, Afshar A (2019) Synthesizing and comparing HA$\mathrm{TiO}_{2}$ and $\mathrm{HA}-\mathrm{ZrO}_{2}$ nanocomposite coatings on 316 stainless steel. SN Appl Sci 1(2):155

28. Huseyin S, Kurnaz SC (2006) Properties of alumina particulate reinforced aluminum alloy produced by pressure die casting. Mater Des 27:676-683 
29. Dinesh A, Basavarajappa S (2004) Dry sliding wear studies on hybrid MMC's-a Taguchi technique. In: International symposium of research students on materials science and engineering

30. Smith BC (2011) Fundamentals of Fourier transform infrared spectroscopy. CRC Press, Boca Raton

31. Ramesh CS, Ahamed A (2011) Friction and wear behaviour of cast Al 6063 based in situ metal matrix composites. Wear 271(9-10):1928-1939

32. Meti VKV, Konaraddi R, Siddhalingeshwar IG (2018) Mechanical and tribological properties of AA7075 based MMC processed through ultrasound assisted casting technique. Mater Today Proc 5(11):25677-25687
33. Bhushan B (1999) Principles and applications of tribology. Wiley, Hoboken

34. Singh KK, Singh S, Shrivastava AK (2016) Study of tribological behavior of silicon carbide based aluminum metal matrix composites under dry and lubricated environment. Adv Mater Sci Eng 2016:3813412

Publisher's Note Springer Nature remains neutral with regard to jurisdictional claims in published maps and institutional affiliations. 